\title{
Should anti-tobacco media messages be culturally targeted for Indigenous populations? A systematic review and narrative synthesis
}

\author{
Gillian Sandra Gould, ${ }^{1}$ Andy McEwen, ${ }^{2}$ Tracey Watters, ${ }^{3}$ Alan R Clough, ${ }^{4}$ \\ Rick van der Zwan ${ }^{5}$
}

${ }^{1}$ School of Public Health,

Tropical Medicine and

Rehabilitation Sciences, James

Cook University, Townsville,

Queensland, Australia

${ }^{2}$ Cancer Research UK Health

Behaviour Research Centre,

Epidemiology and Public Health

University College London,

London, UK

${ }^{3}$ Southern Cross University, East

Lismore, New South Wales,

Australia

${ }^{4}$ School of Public Health,

Tropical Medicine and

Rehabilitation Sciences, James

Cook University, Townsville,

Queensland, Australia

${ }^{5}$ Rural Clinical School, University

of New South Wales, Sydney,

New South Wales, Australia

\section{Correspondence to}

Dr Gillian S Gould, P0 Box 9077,

Moonee Beach 2450, NSW

Australia; gillian.gould1@my.

jcu.edu.au

Received 11 January 2012

Accepted 29 July 2012

\section{ABSTRACT}

Objective To summarise published empirical research on culturally targeted anti-tobacco media messages for Indigenous or First Nations people and examine the evidence for the effectiveness of targeted and nontargeted campaigns.

Methods Studies were sought describing mass media and new media interventions for tobacco control or smoking cessation in Indigenous or First Nations populations. Studies of any design were included reporting outcomes of media-based interventions including: cognitions, awareness, recall, intention to quit and quit rates. Then, 2 reviewers independently applied inclusion criteria, which were met by $21(5.8 \%)$ of the studies found. One author extracted data with crosschecking by a second. Both independently assessed papers using Scottish Intercollegiate Guidelines Network (SIGN; quantitative studies) and Daly et al (qualitative studies).

Results A total of 21 studies were found (4 level 1 randomised controlled trials (RCTs), 11 level 2 studies and 6 qualitative studies) and combined with narrative synthesis. Eight evaluated anti-tobacco TV or radio campaigns; two assessed US websites; three New Zealand studies examined mobile phone interventions; five evaluated print media; three evaluated a CD-ROM, a video and an edutainment intervention.

Conclusions Although Indigenous people had good recall of generic anti-tobacco messages, culturally targeted messages were preferred. New Zealand Maori may be less responsive to holistic targeted campaigns, despite their additional benefits, compared to generic fear campaigns. Culturally targeted internet or mobile phone messages appear to be as effective in American Indians and Maori as generic messages in the general population. There is little research comparing the effect of culturally targeted versus generic messages with similar message content in Indigenous people.

\section{INTRODUCTION}

The preamble to the WHO's Framework Convention on Tobacco Control contains statements of deep concern about the high levels of smoking in Indigenous peoples across the globe. ${ }^{1}$ Western countries have experienced a decrease in prevalence of smoking in the general population, but little improvement among the Indigenous or First Nations populations embedded within them. In the general Australian population, for example, smoking prevalence dropped from $34 \%$ in $1980,{ }^{2}$ to
$16.6 \%$ in $2007 .{ }^{3}$ Data available for Indigenous Australian Aboriginal and Torres Strait Islander populations suggests a small decrease from $53 \%$ in $2004,{ }^{4}$ to $50 \%$ nationally in $2008 .^{5}$ Rates were comparable in 2008 for American Indians (49\%), ${ }^{6}$ and New Zealand (NZ) Maori (45\%), ${ }^{7}$ with levels also remaining static. ${ }^{89}$

Traditional mass media anti-tobacco campaigns communicate through television, radio, newspapers, billboards, posters, leaflets or booklets, with the intention of discouraging uptake, encouraging smokers to quit and maintaining abstinence in nonsmokers. ${ }^{10}$ More recently, new media have been incorporated into anti-tobacco campaigns and interventions and are the subject of recent research: these include digital formats with interactive technology such as internet, mobile phone, video and CD-ROMs. ${ }^{11}$ Media campaigns are considered an important component of tobacco control. ${ }^{11}$ Given the lack of change in smoking prevalence in Indigenous populations in Western nation states, compared with the general population in these countries, it seems that anti-tobacco media messages, as one of several influential drivers of cessation, may not yet be reaching their potential. ${ }^{11}$ Other important factors influencing Indigenous smoking cessation such as sociocultural factors, consistent implementation of tobacco control policies in Indigenous and remote communities, and access to treatment, while relevant, are beyond the scope of this review.

Targeted marketing is used in the advertising industry including tobacco advertising. ${ }^{11}$ Targeting is also employed for high-risk population groups with specific health needs or risk factors. The Ottawa charter recommends that health messages should be sensitive and respectful of the cultural needs of diverse populations. ${ }^{12}$ There is no agreed definition of cultural targeting. Kreuter and Skinner propose that targeting involves: "the development of a single intervention approach for a defined population subgroup that takes into account characteristics shared by the subgroup's members.' ${ }^{13}$

Most research on anti-tobacco media interventions has been in general populations of high-income countries. ${ }^{14} 15$ Whether anti-tobacco strategies need to be targeted for minority or disadvantaged subgroups based on divisions such as ethnicity, language or age is debated. ${ }^{11}$ Bala et al, in a Cochrane review of mass media interventions for smoking cessation in adults, found no consistent relationship between campaign effectiveness and ethnicity. ${ }^{10}$ Other evidence suggests anti-tobacco messages 
should be culturally relevant, linguistically clear and reinforced by prominent community members. ${ }^{15}$

The focus of this review is Indigenous populations of Western nation states, who experience similar disadvantages and high smoking prevalence. ${ }^{16}$ Little is known about the optimum delivery of salient anti-tobacco health promotion messages to these Indigenous populations, ${ }^{17} 18$ whether culturally-targeted media messages are needed or, indeed, if tobacco treatment and prevention needs to be targeted at all. ${ }^{19}$

This review examines the available literature for evidence about the impact of anti-tobacco messages in Indigenous and First Nations populations in Australia, New Zealand, USA and Canada. This includes Australian Aboriginal and Torres Strait Islanders, Maori from New Zealand, American Indians, Alaska Natives, First Nations and Inuit from Canada. Studies in Pacific Islanders living in the US state of Hawaii are included. The review is deliberately broad to include motivational and interventional anti-tobacco messages delivered through traditional mass media and new media platforms.

\section{Objectives}

Our aims were (a) to systematically review and summarise the literature describing attitudes and key responses to culturally targeted anti-tobacco messages and (b) identify any differences in effect according to whether the messages were addressed to the target population or aimed at the general population. The evidence was assessed regarding impacts of media-based interventions in the target populations such as cognitions, awareness, recall, intentions to quit and quit rates.

\section{METHODS}

\section{Data sources}

The following databases were searched from their earliest date through to October 2011: Medline, CINAHL, Embase, Psych INFO and Australian databases via Informit (see online appendix 1). Searches used truncated keywords and/or subject headings related to (tobacco or nicotine or smoking) combined with (Indigenous populations or Oceanic Ancestry Group or Aborigine or Torres Strait Islander or Maori or Inuit or First Nations or American Indian or Alaska Natives or Pacific Islanders) and further combined with (communication media or mass media or social marketing or advertising or health promotion or health education or internet or mobile phone or arts or arts therapy). Art was included as a search term as it is often used in health promotion for Indigenous populations. ${ }^{20} 21$ Additionally, hand searches of reference lists of included papers and other literature on Indigenous smoking known to authors supplemented the electronic search.

The selection criteria were: full, peer-reviewed papers of original research on media-based anti-tobacco messages using any study design that included Indigenous populations embedded within Australia, New Zealand, USA and Canada, including Australian Aboriginal or Torres Strait Islanders, NZ Maori, American Indians, Alaska Natives, Pacific Islanders, First Nations or Inuit. Papers were not included if no measurement of outcome or impact was reported, such as knowledge, attitudes, beliefs, message recall, intention to quit or smoke, or quit rates.

Two reviewers (GSG and TW) independently applied the criteria then reached consensus. GSG (a medical practitioner) prescreened publications for relevance. Then GSG and TW (a clinical psychologist) independently screened titles, available abstracts and then full papers to determine eligibility. Discrepancies were resolved by consensus. Of the 489 studies found, after removing 124 duplicates, 21 (5.8\%) met the inclusion criteria. (See supplementary figure 1.)

\section{Data extraction}

One author (GSG) extracted data, with crosschecking by a second (TW). Information recorded included: aim of the study, geographical region, participant demographics, recruitment methods, methods of data collection and analysis, and summary of results.

Methodological quality for quantitative aspects of studies was assessed for hierarchy of evidence and risk of bias using checklists from Scottish Intercollegiate Guidelines Network (SIGN) $50{ }^{22}$ With no similar guidelines for assessing study quality in qualitative research, ${ }^{23}$ we chose an evidence-for-practice theory by Daly et $\mathrm{al}^{24}$ to categorise qualitative and mixed studies into: (1) generalisable studies; (2) conceptual studies; (3) descriptive studies and (4) single case studies.

\section{Data synthesis}

Data synthesis made use of Popay et al's guidelines for narrative synthesis. ${ }^{25}$ No statistical meta-analysis was performed due to the diversity of study designs and approaches included in this review. For preliminary synthesis, studies were divided into five groups: television or radio campaigns, print media, internet studies, mobile (cell) phone studies and other media. As study approaches were diverse, these were categorised into four basic approaches depending upon whether the variables tested were generic messages, targeted messages or comparisons of both.

\section{RESULTS}

Following Popay et al's guidelines, ${ }^{25}$ results are organised first to summarise the basic features of the studies. A preliminary synthesis of findings is then presented describing the key findings for each type of media studied: initially, traditional mass media and then new media. Outcome measures, study designs, quality of studies and approaches are then presented. This is followed by a narrative synthesis, which collates information from across the studies. We then examine the responses to culturally targeted anti-tobacco messages for Indigenous smokers and draw comparisons between targeted and generic messages.

In all, 21 papers reporting on 20 studies met the inclusion criteria. Supplementary table 1 contains full details of each study including aim, location, recruitment, participants, methods and analysis, intervention, key findings and relevant comments.

Table 1 summarises the included studies in terms of the type of media used, type of study and the studied population.

The nine quantitative studies were comprised of: four randomised controlled trials (RCTs), ${ }^{26-29}$ a database analysis, ${ }^{30}$ two post-intervention surveys, ${ }^{31} 32$ and two before and after (BAS) studies. ${ }^{33} 34$ The remaining 12 studies were mixed-methods or qualitative studies, ${ }^{35-46}$ including 4 with a BAS design. ${ }^{35-38}$ No peer-reviewed studies were found describing Canadian First Nations or Inuit. All studies were in community settings covering a range of urban, rural and remote locations. Seven of the studies described the impact of media interventions among youth, ${ }^{27} 293236374142$ and two addressed women, ${ }^{38} 39$ with one of these aimed at pregnant women. ${ }^{38}$ Two studies included health staff or health professionals. ${ }^{40} 43$

\section{Mass media}

Television or radio advertisements

Of the 21 papers, 8 evaluated the impact of anti-tobacco television or radio advertisements on attitudes, beliefs, smoking 
Table 1 Summary of media type and populations of included studies

\begin{tabular}{|c|c|c|c|c|}
\hline Media & $\begin{array}{l}\text { Aboriginal and Torres } \\
\text { Strait Islander } \\
\text { Australians (5 studies) }\end{array}$ & $\begin{array}{l}\text { New Zealand } \\
\text { Maori (7 studies) }\end{array}$ & $\begin{array}{l}\text { US Pacific Islander } \\
\text { and Native Hawaiians } \\
\text { (1 study) }\end{array}$ & $\begin{array}{l}\text { American Indian or } \\
\text { American Indian }+ \\
\text { Alaska Native }\left(7^{*} \text { studies }\right)\end{array}$ \\
\hline $\begin{array}{l}\text { TV and/or radio } \\
\text { advertisements }\end{array}$ & $\begin{array}{l}4 \text { TV/Radio studies ( } 1 \text { mixed, } \\
1 \text { mixed BAS, } 1 \text { survey, } \\
1 \text { qualitative) }\end{array}$ & $\begin{array}{l}3 \text { TV studies (1 database, } \\
1 \text { BAS, } 1 \text { qualitative) }\end{array}$ & & 1 TV/Radio study (survey) \\
\hline Internet & & & & 2 internet studies (1 RCT, 1 qualitative) \\
\hline Mobile phone & & $\begin{array}{l}3 \text { Mobile phone studies } \\
\text { ( } 2 \text { RCT, } 1 \text { mixed BAS) }\end{array}$ & & \\
\hline Print media & & 1 print media study (BAS) & & $\begin{array}{l}3 \text { print media studies ( } 4 \text { papers: } \\
1 \text { RCT, } 2 \text { qualitative, } 1 \text { mixed)* }\end{array}$ \\
\hline Other media: & $1 \mathrm{CD}-\mathrm{ROM}$ intervention (mixed BAS) & & 1 edutainment study (mixed BAS) & 1 Video intervention (mixed BAS) \\
\hline
\end{tabular}

${ }^{*}$ Two papers reported the same study.

BAS, before and after study; RCT, randomised controlled trial.

intentions or behaviour. Three New Zealand studies examined the effect of the collaboratively developed, 'it's about whanau' (IAW) television campaign, targeting Maori smokers. ${ }^{30} 3339$ The first study used a cross-sectional New Zealand-wide survey and Quitline data from two waves: the Quitline monitoring data showed that the proportion of Maori callers to the Quitline increased from $20 \%$ to $25 \%$ post campaign. ${ }^{33}$ The advertisements were rated highly believable (73\%) and relevant (67\%) and over $50 \%$ of Maori survey respondents said the advertisements influenced them to quit. A second study used a focus group of Maori women to elicit their views on a range of smoking cessation initiatives including the IAW campaign, which was seen as portraying enduring values, while fear campaigns by comparison, were considered to have only shortterm effects and be culturally inappropriate. ${ }^{39}$ In contrast, another study reported a greater number of calls by Maori smokers to the Quitline following the screening of an advertising campaign that featured a fear message compared to the screening of the Maori orientated IAW campaign (RR 1.26, 95\% CI 1.08 to 1.46). However although the fear message had some Maori specific content, the advertisements had very different objectives, formats and intentions, and therefore the content was not comparable. ${ }^{30}$

Four papers measured the response of Aboriginal or Torres Strait Islander Australians to television and radio campaigns. ${ }^{31} 354046$ Three studies reported high levels of recall of generic television or radio anti-tobacco advertising, ${ }^{31} 3540$ two of which further assessed self-reported changes in smoking behaviour. ${ }^{31} 35$ Despite good recall (85\%) of the National Tobacco Campaign (NTC), exposure to anti-tobacco interventions (eg, advice, medication and advertisements) did not influence cessation rates among Aboriginal people in three Northern Territory communities $(\mathrm{p}=0.42) .{ }^{35}$ There was similarly high prompted recall $(89.9 \%)$ to the 'Bubblewrap' campaign by Aboriginal smokers in Western Australia, with most survey participants reporting positive changes in attitudes such as thinking about cutting down or quitting (81\%); however only three participants $(1.5 \%)$ reported quitting. ${ }^{31}$ Similarly, Indigenous community members and health staff had 'good recall' of TV campaigns when questioned about different tobacco interventions, although health staff believed TV advertisements should be more targeted to Indigenous smokers. ${ }^{40}$ There was a non-significant difference in how Australian Indigenous and non-Indigenous viewers rated TV advertisements featuring strong graphic imagery and personal narratives on a range of outcome measures. These included message acceptance (combined ratings for 'understanding', 'believable' and 'relevant') and personalised effectiveness (combined ratings of 'made me stop and think', 'concerned about smoking', 'more likely to try to quit' and 'provided good reasons to quit') ${ }^{46}$ Similarly, American Indian students showed no differences compared to students from the general population in how they rated the most popular threat based TV advertisement with 'Artery' rated highest for 'afraid' and 'disgust'. ${ }^{32}$

\section{Print media}

The print media studies showed varied effects. Improved pack health warnings (PHW) resulted in similar significant increases in recognition of the Quitline number $(p<0.001)$, pre/post campaign, for Maori (25.1\% increase) and the general New Zealand population (24.1\%). ${ }^{34}$ Two US papers assessed the feasibility of adapting the 'Second Wind' program for pan-tribal populations. Participants representing 17 different tribal groups suggested improving Native design elements, including a Native worldview, oral history, family content and traditional tobacco use. ${ }^{44}$ A three-part systematic strategy was used to assess the 'All Nations Breath of Life' educational brochures for scientific accuracy, readability and cultural appropriateness for American Indian and Alaska Native smokers. The authors propose this strategy as a way to enhance the cultural suitability of print materials, prior to conducting a clinical trial. ${ }^{43}$ Anti-tobacco messages embedded into a mailed-out Native art calendar for American Indians and Alaska Natives did not increase the uptake of smoking cessation advice or nicotine patch prescription (as determined by an audit of the patient's record), compared with a control calendar without messages. No impact on quit rates was observed (6.3\% vs $7 \%, p=0.33) .{ }^{28}$

\section{New media}

Internet

Two studies, which included American Indians and Alaska Native participants, reported a positive impact from US internet websites. ${ }^{26} 41$ American Indians formed a small percentage of US participants $(2 \% \mathrm{n}=7)$ using a website featuring video clips, in a RCT with a wait-list control. ${ }^{26}$ On logistical regression there were no significant interactions between ethnicity and condition therefore self-reported quit rates were reported as one group (treatment group $12.3 \%$ vs control $5 \%$ at 90 days, OR 2.66). In a two-phase action research pilot project American Indian and Alaska Native participants suggested modifications to the generic SmokingZine website to make it more 'Native'. ${ }^{41}$ Researchers then compared use of the generic website with the culturally adapted website for American Indian/Alaska Native youth. Usability scores were moderately in favour for the culturally adapted version compared to the non-modified site. Changes in smoking behaviour were not assessed. 


\section{Mobile phone}

Three New Zealand studies reported mixed outcomes from mobile phone interventions that used text, ${ }^{27}$ and video messages. ${ }^{29}{ }^{42}$ Culturally-adapted text messages were as effective for Maori as generic messages were for non-Maori in the short term, in a four group RCT with controls receiving followup reminder texts only. There were no significant differences between Maori and non-Maori in self-reported quit rates $(26.1 \%$ for Maori in the treatment group vs $11.2 \%$ Maori in control group at 6 weeks, RR: $2.34,95 \%$ CI 1.44 to 3.79 ), and results were similar for non-Maori (RR: $2.16,95 \%$ CI 1.72 to 2.71). This indicates that when Maori are given culturally targeted interventions their quit rates can equal those of the general population. ${ }^{27}$ A collaboratively developed multimedia mobile phone intervention was successfully piloted producing a $53 \%$ self-reported quit rate at a multicultural college, which included Maori. ${ }^{42}$ However when a RCT tested its effectiveness, there was no significant difference in continuous abstinence (intention-to-treat) at 6 months between the smoking cessation video message intervention (26.4\%) and a general health video message control $(27.6 \%),(p=0.8) .{ }^{29}$ No data about the ethnic group of the quitters was provided in the latter two studies, even though Maori were a target group.

\section{Other media}

Three media studies falling outside the above categories had varying effects: one incorporated a CD-ROM, another used an education-entertainment format and a third used a DVD. An Aboriginal Australian community based program employed a CD-ROM, which was well received and used by participating youth, however there were no changes in self-reported smoking behaviours. ${ }^{37}$ An education-entertainment multimedia drama performance improved knowledge about addiction $(p=0.021)$ and decreased future intentions to smoke $(p=0.041)$ in Native Hawaiians and Pacific Islanders in Hawaii, USA. ${ }^{36}$ In contrast, a study with the intervention group using a culturally-targeted video, counselling and brochures, and the control group receiving brief interventions and brochures only, had poor levels of acceptance and did not change smoking behaviour in pregnant Alaska Native women. ${ }^{38}$

\section{Outcome measures}

Table 2 demonstrates the diversity of outcome measures. A total of 12 studies measured cultural suitability ${ }^{38-41} 43-45$ and/or relevance. $^{26} 2931 \quad 33 \quad 43-46$ Only three studies measured believability, ${ }^{26} 3146$ which is one of the hallmarks of a salient message. Usability was confined mostly to those delivery systems, such as mobile phone and internet, which demanded interactivity on a technical basis. ${ }^{26} 2941424445$ Awareness and recall of the messages or campaign was a common feature ${ }^{31-36} 3840$ : a standard approach is to ask for unprompted then prompted recall, ${ }^{11}$ however the type of recall in some studies was unspecified. ${ }^{35} 40$ One study had a sophisticated measure of perceived effectiveness and confirmed recall. ${ }^{32}$ The assessment of smoking attitudes and behaviour varied across the studies and included measuring attitudes to quitting, ${ }^{3346}$ intentions to quit or smoke, ${ }^{26} 323336$ quit attempts, ${ }^{29} 3138$ levels of consumption, ${ }^{26} 42$ perceptions about being influenced to quit by the message (including talking to others about quitting), ${ }^{3133} 35$ calls to a Quitline, ${ }^{3033}$ receipt of cessation advice, ${ }^{28}$ and quit rates. ${ }^{26} 27293135384142$

Standardised reporting of smoking abstinence, which is considered best practice, was missing from most of the studies. ${ }^{47} 48$ Only three studies described how they assessed self-reported quit status: consumption over the last 7 days, ${ }^{26} 2938$ while three studies biochemically validated abstinence, ${ }^{27} 2938$ with one using the Russell Standard for continuous abstinence. ${ }^{29}$

\section{Study designs and quality of evidence}

Table 3 summarises the studies and their level of evidence (SIGN and Daly et al). Due to the small number of studies in this field, we did not exclude studies on the basis of their quality ranking, but rather gave greater weight to the higher-level studies. Four quantitative studies were rated as level $1+$ or $1++($ SIGN $),{ }^{22}$ which indicates they are higher quality and have a lower risk of bias. $^{21-24}$ One further cohort study was considered $2+$, therefore of good quality for its type. ${ }^{46}$ Of the 15 quantitative studies, 10 received a minus score for SIGN ranking, that is the studies were considered to have a high risk of bias.

Nine papers containing qualitative elements were rated using Daly et al's hierarchy of evidence for practice. ${ }^{24}$ Two mixedmethods studies reported insufficient qualitative details to be assessed. Only two papers were rated as category 2 , that is as conceptual, ${ }^{38} 44$ and therefore potentially transferable to other populations, ${ }^{24}$ while none were ranked in the top category. Seven other papers rated as category 3 were therefore deemed descriptive. ${ }^{35} 39-4345$

\section{Study approaches}

There was a wide variety of research approaches making comparisons between non-equivalent population groups and interventions difficult. Figure 1 illustrates the study approaches, which can be categorised into four conceptual groups as follows:

1. Effect of generic media on Indigenous people \pm comparison with general population. ${ }^{31} 3234354046$

2. Generic versus targeted for Indigenous people (in this case the interventions had non-equivalent content). ${ }^{30}$

3. Generic for general population versus targeted for Indigenous population. 26272942

4. Effect of targeted campaigns for Indigenous or measures of cultural suitability. ${ }^{28} 33$ 36-39 $4143-45$

Of the 21 papers, 16 had some degree of specificity to the target population or choice of culturally targeted elements. Eight studies described a formative phase in collaboration with the target audiences, ${ }^{27-28} 33$ 36-38 4142 in order to target the intervention.

\section{NARRATIVE SYNTHESIS}

\section{Responses to culturally targeted anti-tobacco messages}

The qualitative studies revealed a preference for culturally targeted messages. This held true across the populations studied. US participants from pan-tribal Nations recommended that resources should become more inclusive of other Nations' views by: use of appropriately diverse cultural design elements; depicting a broader range of tribal customs; and increasing education about ceremonial tobacco use. ${ }^{44} 45$ American Native youth preferred using a website with a more 'Native' look and advised how to adapt a generic site by incorporating Native design features. ${ }^{41}$ In Australia, health and welfare staff, working with Indigenous communities, favoured culturally appropriate messages and suggested that modifications were required for an Indigenous audience. ${ }^{40}$ Stewart et al tested one Indigenous targeted TV advertisement that was rated significantly higher, by Indigenous compared to non-Indigenous smokers, for message acceptance and personalised effectiveness. ${ }^{46}$ Indigenous viewers related more to the advertisement and were more likely to discuss it than non-Indigenous viewers. NZ Maori similarly call for more culturally relevant advertisements, ${ }^{39}$ and point out that mainstream graphic advertisements showing body parts, are inappropriate or tapu. ${ }^{39}$ The culturally targeted IAW 


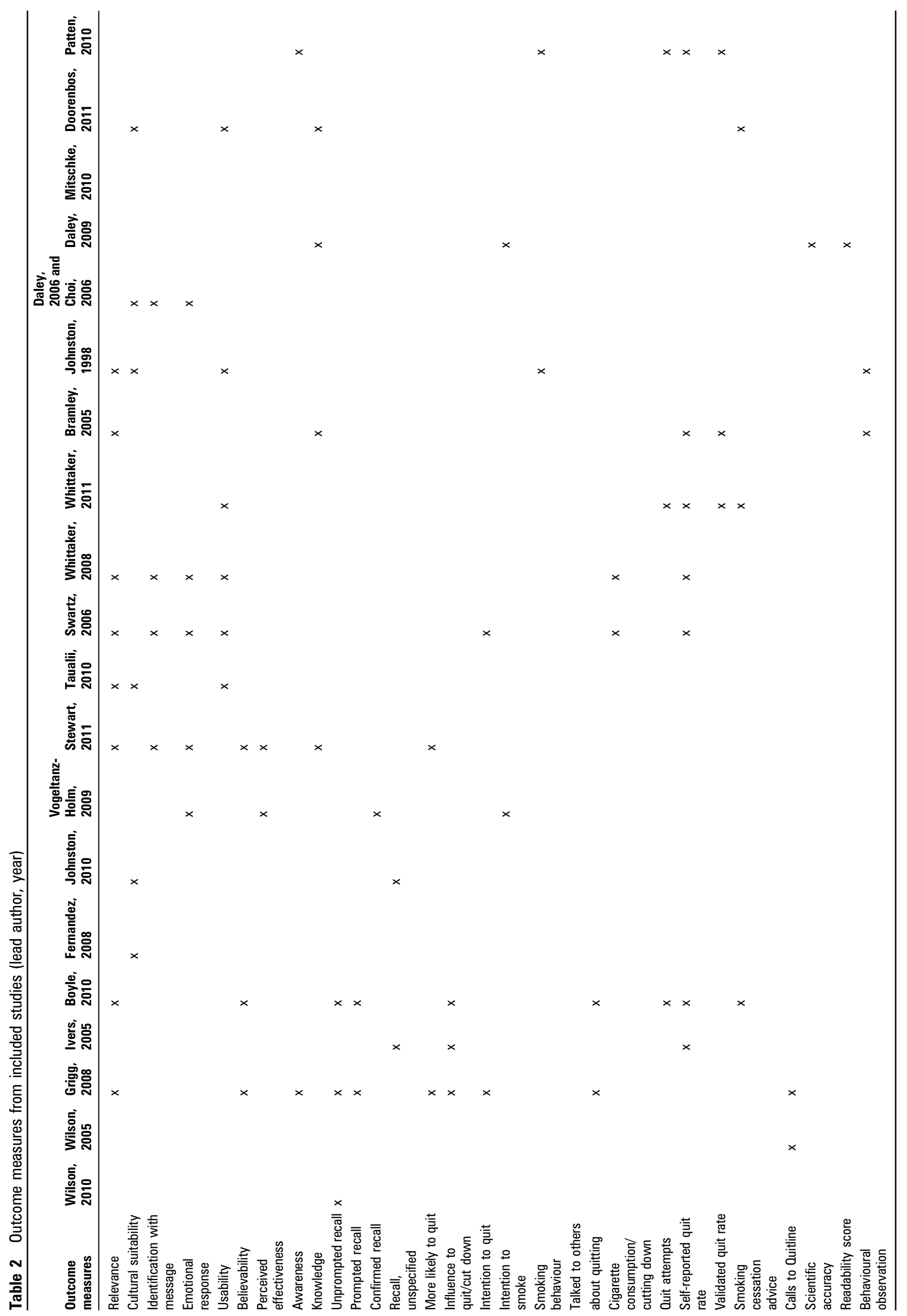


<smiles>CCCCC</smiles>

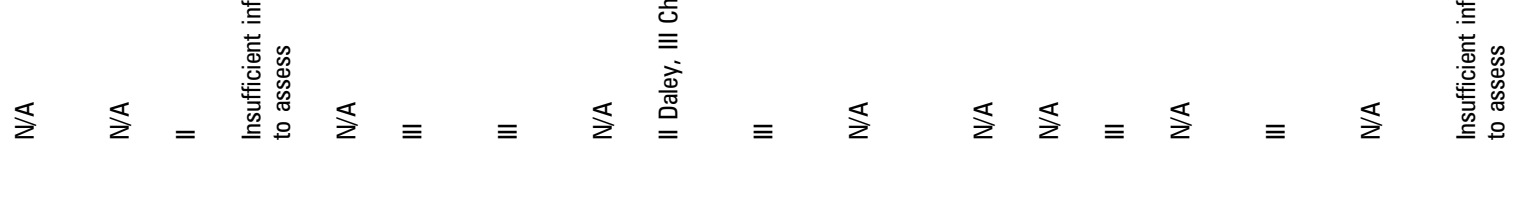

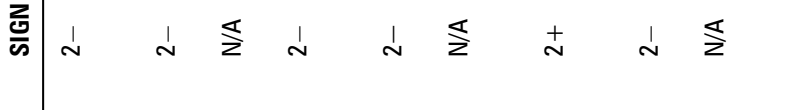

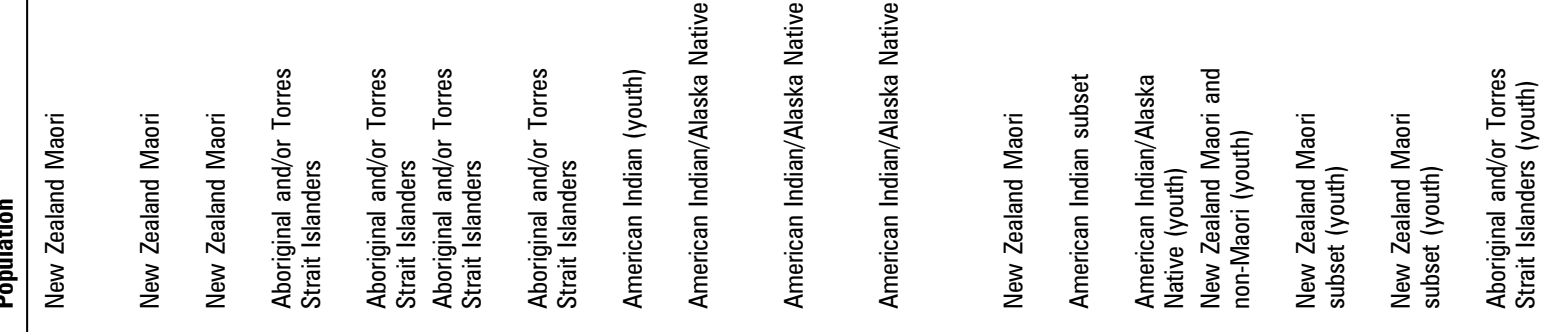

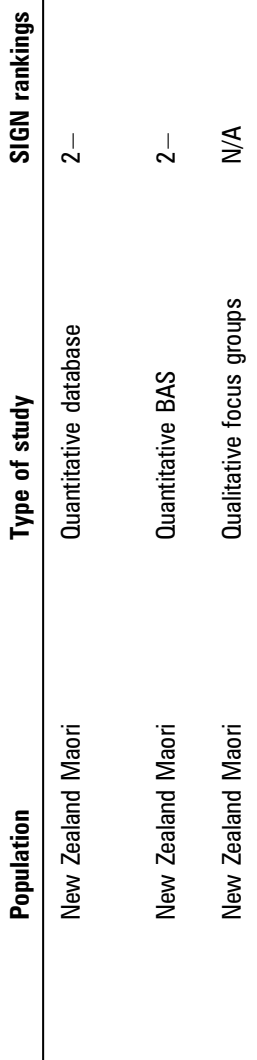

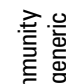

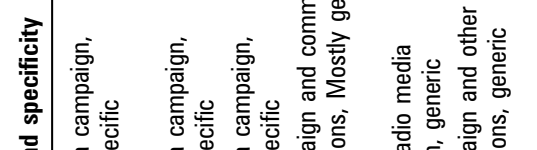

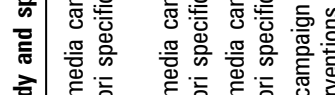

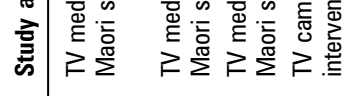

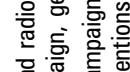

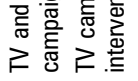

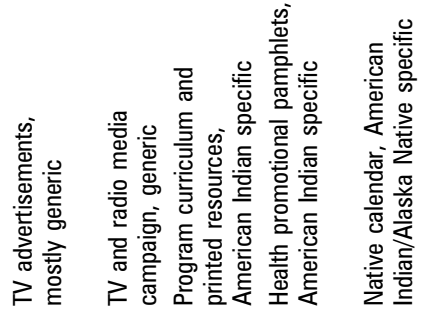

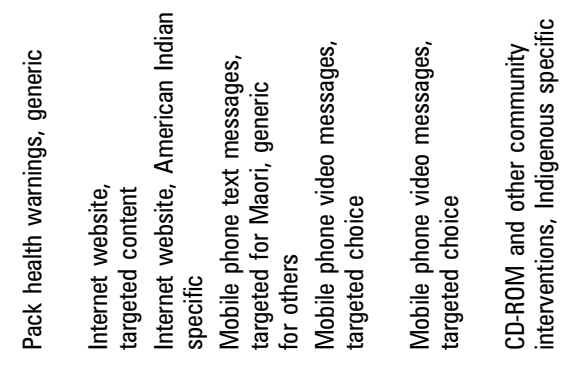




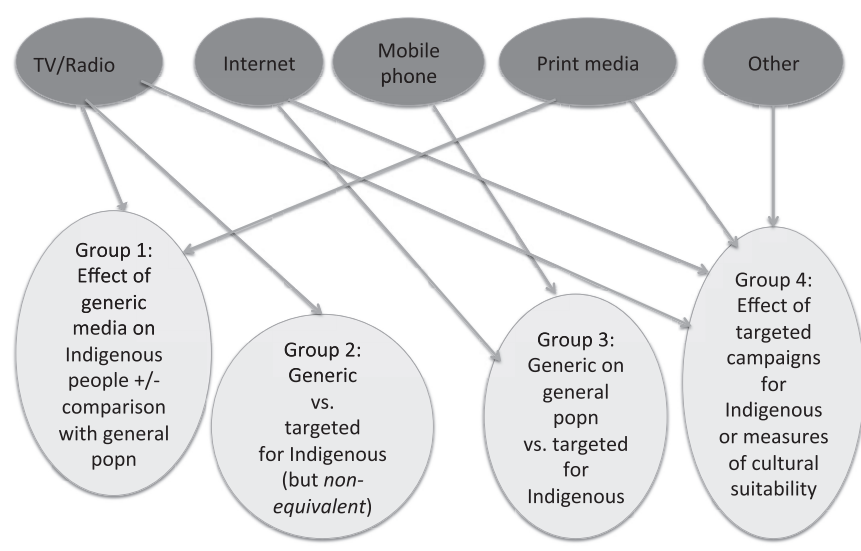

Figure 1 Schema of included studies illustrating conceptual groups $1-4$.

campaign increased calls to Quitline and recall of tobacco advertisements in Maori. ${ }^{33}$ Although graphic advertisements stimulated more calls by Maori to the NZ Quitline than the IAW campaign, ${ }^{29}$ less robust qualitative data suggests tacit value in the culturally targeted campaign. ${ }^{39}$ Emotional engagement and identification is considered a key feature of nicotine dependence, ${ }^{49}$ and also to successful implementation of entertainment-education. ${ }^{50}$ Mitschke et al's study of a culturally targeted tobacco prevention drama for Asian and Pacific Islander and Native youth in Hawaii was the only study in this review that specifically measured the level of emotional engagement with the characters and identification with the messages. ${ }^{36}$ Analyses demonstrated a significant difference in knowledge after the drama and significant improvements in intention to avoid smoking.

\section{Effects of generic and targeted anti-tobacco messages on Indigenous people}

There is weak evidence from five studies that generic messages (devised for the wider population), can be as effective in terms of recall for the Indigenous population as the general population, when tested in Aboriginal or Torres Strait Islanders and NZ Maori. ${ }^{31} 32343540$ There is evidence against the ability to recall a generic advertisement in the target population translating into increased quit rates as exemplified by Iver et al's study, ${ }^{35}$ and discussed by Johnston and Thomas, ${ }^{40}$ and Vogeltanz-Holm et al in the US. ${ }^{32}$ Stewart et al found that Indigenous and nonIndigenous viewers shown a broad range of advertisements in an experimental study rated those containing strong graphic imagery or personal narratives as effective for a range of measures including being more likely to quit. ${ }^{46}$ Where there was a significant difference, ratings by Indigenous viewers were always higher for graphic and narrative advertisements than those given by the non-Indigenous viewers. A study on new PHW found no significant differences in improved recognition of generic tobacco messages between the New Zealand general population and Maori. ${ }^{34}$ It can be argued that wholly graphic non-targeted messages such as 'Artery' ${ }^{32}$ and $\mathrm{PHWs}^{29}$ may be culturally neutral. Indigenous viewers commented that advertisements such as 'Bubblewrap' and 'Alive' targeted everyone as they depicted body parts only. ${ }^{46}$ Conversely the showing of body parts can render messages tapu for Maori. ${ }^{39}$

Several studies compared culturally targeted content for the Indigenous population with generic (non-targeted) content for the rest of the population. In these cases there is evidence from two level 1 studies using culturally targeted content 
demonstrating the approaches were equally effective on quit rates in the short term (6-12 weeks) when comparing responses of the Indigenous samples to the general population samples. $^{26} 27$ The New Zealand text messaging study, which deliberately over-recruited Maori to eliminate health inequality bias (21\% Maori participants compared with 14.7\% Maori in the New Zealand population), had equivalent Maori to non-Maori self-reported quit rates. ${ }^{27}$ In contrast, the US study of an automated website with video content had only a small percentage of American Indian participants $(2 \% n=7)$, however it found no significant interactions between ethnicity for any of the ethnic subgroups, including American Indians, and treatment or control condition on logistical regression. ${ }^{26}$ When a generic threat campaign was measured head-to-head with a targeted holistic Maori campaign, in regard to calls to the Quitline, it appeared the generic threat campaign was more effective. ${ }^{30}$

\section{DISCUSSION \\ Should anti-tobacco media messages be culturally targeted for Indigenous people?}

Despite qualitative evidence that Indigenous populations prefer culturally targeted messages, there is early evidence of effective recall or recognition of generic messages in the Indigenous cohorts. There is also preliminary evidence that culturally targeted messages can be as effective in Indigenous populations in the short term, as generic (non-targeted) messages are for the general population. Market research supports the view that resources that depict Indigenous faces will be more engaging to an Indigenous audience, ${ }^{18}$ except perhaps for youth who relate more to the dominant youth culture. ${ }^{51}$ Indigenous people may also be wary of negative stereotyping in the media. ${ }^{52}$ Mounting culturally targeted mass media campaigns for Indigenous smokers, through mass media, may demand a substantial financial investment, for a return that is still as yet uncertain.

This review revealed disparity in the sophistication of media studies in different countries for Indigenous tobacco control. New Zealand has the most comprehensive culturally targeted mass media campaign for its Indigenous people and has trialled mobile phones to deliver anti-tobacco messages to Maori with varying success. ${ }^{29} 3033$ Although Australia's National Tobacco Campaign included some targeted TV and radio advertisements, ${ }^{51}$ Australia has only recently invested in a national culturally targeted mass media campaign. ${ }^{53}$

Internet-based programs for Indigenous populations and drama appear to be promising interventions, but were only evident in the US. There were several US studies on print media, but no evidence so far that videos for pregnant Alaska Native women, or mailed out print media for American Indians are effective. Notable was a lack of peer-reviewed papers on interventions in Canadian First Nations and Inuit. Those Western countries that have Indigenous citizens can learn from each other's exemplars and trial different targeted approaches to attempt to drive down smoking prevalence.

In light of the importance of transportation and self-referencing for influencing intentions to quit smoking, the case for culturally targeted anti-tobacco media interventions is compelling although methodologically challenging. ${ }^{11}{ }^{54}$ Effectiveness of interventions is not the sole consideration when implementing interventions in Indigenous populations, particularly in the early, formative stages. Promoting community ownership, selfdetermination and acceptability are important aims. ${ }^{55}$ Emotional engagement and identification is also plausibly higher if the targeted community has been involved in formative research, whichever the media used. ${ }^{56} 57$ These elements can be accomplished through community-based participatory research (CBPR), ${ }^{58}$ however higher levels of evidence, afforded by randomised controlled trials, may be unobtainable in community based health promotion programs. ${ }^{59}$

The importance of going beyond tests of cultural appropriateness, acceptability and feasibility to establish effectiveness is illustrated. Some culturally targeted media interventions: the art calendar for American Indians/Alaska Natives, ${ }^{28}$ the video for pregnant Alaska Native women ${ }^{38}$ and the New Zealand video mobile phone intervention, ${ }^{29}$ were no more effective than the control intervention despite being collaboratively developed. The latter two studies were hampered with recruitment issues, with few Indigenous people being ready to quit. The degree to which interventions are culturally sensitive may potentially influence effectiveness. Superficial strategies (such as matching language and themes) may increase receptivity to the message, whereas deeper strategies (targeting sociocultural beliefs influencing health behaviour) convey salience. ${ }^{60}$ An evidence-based method to ensure cultural suitability, readability and accuracy of tobacco control messages is fundamental. The protocol suggested by Daley et al could have a worthy application to resource development for print media. ${ }^{43}$ Researchers in New Zealand are commended for their avoidance of cultural bias by a using a boosted sample of Maori participants, ${ }^{27} 2933$ and conducting and reporting research within a Maori framework. ${ }^{27} 3339$

Mass media campaigns can be drivers for prompting quit attempts. While many smokers are able to quit unassisted, ${ }^{61}$ the success of individual quit attempts are significantly improved though use of behavioural support and medications. ${ }^{62}{ }^{63}$ It is documented that mass media campaigns are more effective when supported by comprehensive programs, which may include improved access to treatment. ${ }^{11}$ Little is yet known about the natural history of quitting for an Indigenous smoker. In the interim, steps need to be taken to ensure that Indigenous populations are not disadvantaged by inequities in access to media broadcasting, ${ }^{64}$ IT technology ${ }^{65}$ and effective treatments, should they wish or need to use them. ${ }^{66}$

This review found an absence of a common taxonomy in Indigenous studies to describe media-based interventions. It also found precise outcome measures are not used routinely, for example for measuring perceived effectiveness, recall and quit rates. This reduces the ability to transfer findings and conduct meta-analyses.

\section{Conclusions}

There is a well established evidence base on the effectiveness of anti-tobacco mass media campaigns in the general population. ${ }^{10} 111467$ Yet Indigenous people are one of several disadvantaged groups for whom there is a shortage of robust evidence for either generic or culturally targeted anti-tobacco messages. ${ }^{68}$

Media based research in Indigenous people is diffuse and hindered by a diversity of study approaches and lack of agreed outcome measures. There is limited evidence supporting the need for culturally targeted messages. Preference for culturally targeted messages by Indigenous peoples is acknowledged. Where culturally targeted messages have been trialled campaigns have been shown to be effective in terms of change of knowledge, attitude and behaviour.

Developing messages that are of personal relevance to Indigenous smokers and testing this concept through a well constructed, culturally appropriate campaign, preferably would include longitudinal data to assess whether recall and intentions to quit translate into long-term abstinence. Comparisons 


\section{What this paper adds}

- Indigenous populations have a high prevalence of tobacco smoking, which is not decreasing in line with that of the general population.

- Despite well established evidence for anti-tobacco mass media campaigns for the general population, there is limited evidence for the use of anti-tobacco messages for Indigenous people.

- This review brings together empirical evidence for culturally targeted and generic anti-tobacco messages for Indigenous populations in North America, New Zealand and Australia.

- Although Indigenous smokers recall generic anti-tobacco messages, this review also supports the need for culturally targeted messages. Targeted messages for Indigenous smokers are shown here to effectively change knowledge, attitudes and smoking behaviour, and persist as a preferred option.

- This paper highlights the need for a well constructed trial comparing generic versus targeted messages with similar content for Indigenous smokers.

between targeted and non-targeted campaigns furthermore need to test equivalent genres in order to lay down a proof of principle.

Contributors GSG is lead researcher for this review, conceived the study, designed and conducted the search, reviewed papers for inclusion, assessed study quality. formulated the tables and figures, interpreted data, formed and interpreted the synthesis and wrote the manuscript. AMcE advised on design of review, search strategy, structure of the paper, interpretation of data and critically reviewed all drafts. TW independently reviewed papers for inclusion and quality, crosschecked data tables and critically reviewed drafts. ARC advised on the structure of the paper, interpretation of data, and critically reviewed and edited drafts. RvdZ advised on the concept and design of the review, search strategy, structure of the paper and critically reviewed initial drafts. All authors read and approved the final manuscript.

Funding This work was supported by a National Health and Medical Research Council (Australia) and National Heart Foundation (Australia) cofunded postgraduate training scholarship for Indigenous Health Research, grant number APP1039759.

Competing interests None.

Provenance and peer review Not commissioned; externally peer reviewed.

\section{REFERENCES}

1. World Health Organization. Framework Convention on Tobacco Control. Geneva, Switzerland: WHO Document Production Services, 2005. ISBN 9241591013.

2. Winstanley $\mathbf{M}$, White $V$. Chapter 1 - tobacco in Australia: facts and issues. In: Scollo MM, Winstanley MH, eds. Tobacco in Australia: Facts and Issues. 3rd edn Melbourne: Cancer Council Victoria, 2008.

3. Australian Institute of Health and Welfare. 2007 National Drug Strategy Household Survey: Detailed findings, Drug Statistics Series No. 22, Cat 2. No. PHE 107. Canberra: AlHW, 2008

4. Australian Institute of Health and Welfare. Substance Use Among Aboriginal and Torres Strait Islander People. Cat no IHW 40. Canberra: AlHW, 2011.

5. Thomas DP. Smoking prevalence trends in Indigenous Australians, 1994-2004: a typical rather than an exceptional epidemic. Int J Equity Health 2009;8:37.

6. US Department of Health and Human Services. National Survey on Drug Use \& Health [Internet]; 2008. 2009. http://www.oas.samhsa.gov/nsduh/reports.htm (accessed 22 Dec 2011).

7. New Zealand Ministry of Health. New Zealand Tobacco Use Survey [Internet]; 2008. 2011. http://www.moh.govt.nz/moh.nsf/indexmh/tobacco-trends-2008appendix (accessed 22 Dec 2011).

8. Ministry of Health. Maori Smoking and Tobacco Use. Wellington: Ministry of Health, 2011.

9. American lung association research and program services epidemiology and statistics unit. Trends Tob Use. 2011.

10. Bala M, Strzeszynski L, Cahill K. Mass media interventions for smoking cessation in adults. Cochrane Database Syst Rev 2008;(1):CD004704.

11. National Cancer Institute. The Role of the Media in Promoting and Reducing Tobacco Use. Tobacco Control Monograph No. 19. Department of Health and Human
Services, National Institutes of Health. NIH Pub. No. 07-6242. Bethesda, MD: USA National Cancer Institute, June 2008.

12. WHO. Ottawa Charter For Health Promotion. Ottawa: First International Conference on Health Promotion, 1986. http://www.who.int/hpr/NPH/docs/ottawa_charter_hp.pdf

13. Kreuter MW, Skinner CS. Tailoring, what's in a name? Health Edu Res 2000;15:1-4.

14. Wakefield MA, Loken B, Hornik RC. Use of mass media campaigns to change health behaviour. Lancet 2010;376:1261-71.

15. Baker A, Ivers RG, Bowman J, et al. Where there's smoke, there's fire: high prevalence of smoking among some sub-populations and recommendations for intervention. Drug Alcohol Rev 2006;25:85-96.

16. Kunitz SJ. Disease and Social Diversity: The European Impact on the Health of Non-Europeans. New York, NY: Oxford University Press, 1994. ISBN. 0-19-510869-8.

17. Ivers R. Anti-Tobacco Programs For Aboriginal And Torres Strait Islander People Produced For The Closing The Gap Clearinghouse. Canberra: Australian Institute of Health and Welfare \& Melbourne: Australian Institute of Family Studies, 2011. Cat. no. IHW 37. ISBN 978-1 74249-116 5.

18. Department of Health and Ageing. Developmental Research to inform the National Action to Reduce Smoking Rates Social Marketing Campaign, 2010. http://www. health.gov.au/internet/ctg/publishing.nst/Content/development-market-research (accessed 20 Nov 2011).

19. Stolberg VB. A cross-cultural and historical survey of tobacco use amongst various ethnic groups. J Ethn Subst Abuse 2008;6:9-80.

20. O'Connor M L, Parker E, Mielklejohn B, et al. Heart health education resources for Aboriginal and torres strait islander communities: the health worker's view. Aborig Is Health Work J 1999;23:20-3.

21. Australian Medical Association \& Australian Pharmaceutical Manufacturer's Association. Indigenous Smoking: Issues and Responses. Canberra: Australian Medical Association \& Australian Pharmaceutical Manufacturer's Association, 2000.

22. Scottish Intercollegiate Guidelines Network. SIGN 50: A Guideline Developer's Handbook. Guideline No. 50. Section 7: Forming Guideline Recommendations. UK, Edinburgh: Scottish Intercollegiate Guidelines Network, 2011. ISBN 19781905813254

23. Sale JE, Hawker GA. Critical appraisal of qualitative research in clinical journals challenged. Arthritis Rheum 2005:53:314-15.

24. Daly J, Willis K, Small R, et al. A hierarchy of evidence for assessing qualitative health research. J Clin Epidemiol 2007;60:43-9.

25. Popay J, Roberts H, Sowden A, Petticrew M, et al. Guidance on the Conduct Of Narrative Synthesis In Systematic Reviews. A Product from the ESRC Methods Programme. Version 1. Swindon: Economic and Social Research Council, 2006.

26. Swartz LH, Noell JW, Schroeder SW, et al. A randomised control study of a fully automated internet based smoking cessation programme. Tob Control 2006:15:7-12.

27. Bramley D, Riddell T, Whittaker R, et al. Smoking cessation using mobile phone tex messaging is as effective in Maori as non-Maori. N Z Med J 2005;118:U1494.

28. Doorenbos AZ, Jacobsen C, Corpuz R, et al. A Randomized controlled calendar mailout to increase cancer screening among urban American Indian and Alaska Native patients. J Canc Educ 2011;26:549-54.

29. Whittaker R, Dorey E, Bramley D, et al. A theory-based video messaging mobile phone intervention for smoking cessation: randomized controlled trial. J Med Internet Res 2011;13:e10.

30. Wilson N, Grigg M, Graham L, et al. The effectiveness of television advertising campaigns on generating calls to a national quitline by Maori. Tob Control 2005; 14:284-6.

31. Boyle T, Shepherd CCJ, Pearson G, et al. Awareness and impact of the 'Bubblewrap' advertising campaign among Aboriginal smokers in Western Australia. Tob Control 2010;19:83-6.

32. Vogeltanz-Holm N, Holm J, White Plume J, et al. Confirmed recall and perceived effectiveness of tobacco counter marketing media in rural youth. Prev Sci 2009;10:325-34.

33. Grigg M, Waa A, Bradbrook SK. Response to an Indigenous smoking cessation media campaign: it's about whanau. Aust N Z J Public Health 2008;32:559-64.

34. Wilson N, Weerasekera $D$, Hoek J, et al. Smoker recognition of a national quitline number following introduction of improved pack warnings: ITC Project New Zealand. Nicotine Tob Res 2010:12(Suppl 1):S72-7.

35. Ivers R, Castro A, Parfitt D, et al. Television and delivery of health promotion programs to remote Aboriginal communities. Health Promot J Austr 2005;16:155-8.

36. Mitschke DB, Loebl K, Tatafu E Jr, et al. Using drama to prevent teen smoking development, implementation, and evaluation of crossroads in Hawai'i. Health Promot Pract 2010;11:244-8

37. Johnston F, Beecham R, Dalgleish P, et al. The Maningrida 'Be Smoke Free' project. Health Promot J Austr 1998;8:12-17.

38. Patten CA, Windsor RA, Renner CC, et al. Feasibility of a tobacco cessation intervention for pregnant Alaska Native women. Nicotine Tob Res 2010;12:79-87.

39. Fernandez C, Wilson D. Maori women's views on smoking cessation initiatives. Nurs Prax N Z 2008:24:27-40.

40. Johnston V, Thomas DP. What works in Indigenous tobacco control? The perceptions of remote Indigenous community members and health staff. Health Promot J Austr 2010;21:45-50.

41. Taualii M, Bush N, Bowen DJ, et al. Adaptation of a smoking cessation and prevention website for urban American Indian/Alaska Native youth. J Cancer Educ 2010;25:23-31 
42. Whittaker R, Maddison $\mathrm{R}, \mathrm{McRobbie} \mathrm{H}$, et al. A multimedia mobile phone-based youth smoking cessation intervention: findings from content development and piloting studies. J Med Internet Res 2008:10:e49.

43. Daley CM, Cowan P, Nollen NL, et al. Assessing the scientific accuracy, readability, and cultural appropriateness of a culturally targeted smoking cessation program for American Indians. Health Promot Pract 2009:10:386-93.

44. Choi WS, Daley CM, James A, et al. Beliefs and attitudes regarding smoking cessation among American Indians: a pilot study. Ethn Dis 2006;16:35-40.

45. Daley CM, James A, Barnoskie RS, et al. "Tobacco has a purpose, not just a past": feasibility of developing a culturally appropriate smoking cessation program for a pantribal native population. Med Anthropol 0 2006;20:421-40.

46. Stewart HS, Bowden JA, Bayly MC, et al. Potential effectiveness of specific antitobacco mass media advertisements among Australian Indigenous smokers. Health Educ Res 2011;26:961-75.

47. West R, Hajek P, Stead L, et al. Outcome criteria in smoking cessation trials: proposal for a common standard. Addiction 2005:100:299-303.

48. SRNT Subcommittee on Biochemical Verification. Biochemical verification of tobacco use and cessation. Nicotine Tob Res 2002;4:149-59.

49. West R. Theory of Addiction. Oxford: Blackwell, 2006

50. Kincaid D. Drama, emotion and cultural convergence. Commun Theory 2002;12:136-52.

51. Commonwealth Department of Health and Aged Care. In: Hassard K, ed. Australia's National Tobacco Campaign: Evaluation Report, Volume 1, Chapter 6. Canberra: Department of Health and Aged Care, 1999. ISBN 0642393974.

52. Fleras A. Please Adjust Your Set: Media and Minorities in a Multicultural Society In: Singer B, ed. Toronto: Nelson Canada, 1995.

53. Australian Government National Tobacco Campaign-Break the Chain [Internet]. 2011. http://www.quitnow.gov.au/Internet/quitnow/publishing.nsf/Content/ntcbreak-the-chain (accessed 20 Nov 2011)

54. Dunlop SM, Wakefield M, Kashima Y. Pathways to persuasion: cognitive and experiential responses to health-promoting mass media messages. Commun Res 2010;37:133-64.
55. Ivers RG. An evidence based approach to planning tobacco interventions for Aboriginal people. Drug Alcohol Rev 2004;23:5-9.

56. Brady M. Vaccinating with Videos?: A Preliminary Assessment of HIVIAIDS Media Strategies for Aboriginal and Torres Strait Islander People Commonwealth of Australia. Canberra: Australian Government Publishing Service, 1994.

57. Egger G, Spark R, Donovan R. Health And The Media: Principles And Practices For Health Promotion. Australia: McGraw-Hill, 1993. ISBN: 978-0074700006.

58. Minkler M, Wallerstein N, Budd H, eds. Community-based Participatory Research for Health. 2nd edn. San Francisco: Jossey-Bass, 2008.

59. Nutbeam D. The challenge to provide 'evidence' in health promotion. Health Promot Int 1999;14:99-101.

60. Resnicow K, Soler R, Braithwaite RL, et al. Cultural sensitivity in substance use prevention. J Comm Pysch 2000;28:271-90.

61. Chapman S, MacKenzie R. The global research neglect of unassisted smoking cessation: causes and consequences. PLoS Med 2010;7:e1000216.

62. Fiore MC, Jaen CR, Baker TB, et al. Treating Tobacco Use And Dependence: 2008 Update. Rockville MD: USDHHS U.S Public Health Serv, 2008.

63. West R, McNeill A, Raw M. Smoking cessation guidelines for health professionals: an update. Thorax 2000;55:987-99.

64. Niederdeppe J, Kuang $X$, Crock B, et al. Media campaigns to promote smoking cessation among socioeconomically disadvantaged populations: what do we know, what do we need to learn, and what should we do now? Soc Sci Med 2008;67:1343-55.

65. Dyson LE, Hendriks M, Grant S. eds. Information Technology And Indigenous People. Hershey, USA: Information Science Publishing, 2007.

66. DiGiacomo M, Davidson PM, Abbott PA, et al. Smoking cessation in Indigenous populations of Australia, New Zealand, Canada, and the United States: elements of effective interventions. Int J Environ Res Public Health 2011;8:388-410.

67. Brinn MP, Carson KV, Esterman AJ, et al. Mass media interventions for preventing smoking in young people. Cochrane Database Syst Rev 2010;(11):CD001006.

68. Bryant J, Bonevski B, Paul C, et al. A systematic review and meta-analysis of the effectiveness of behavioural smoking cessation interventions in selected disadvantaged groups. Addiction 2011;106:1568-85 